\title{
Application of the Photoelastic Coating Technique in Car Suspension Failure Analysis
}

\author{
Ludomir J. Jankowski ${ }^{1, a}{ }^{*}$, Marek Reksa ${ }^{1, b}$, \\ ${ }^{1}$ Wroclaw University of Science and Technology, Faculty of Mechanical Engineering, \\ 50-370 Wroclaw, Poland

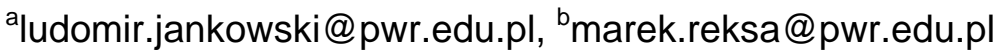

Keywords: Trailing Arm Failure, Photoelastic Coating Technique, Fatique Fracture

\begin{abstract}
The article presents the results of an experiment carried out to determine the cause of damage to the right rear trailing arm of a passenger car. The routine inspection of the vehicle and the test of the arm damaged during the running have indicated production defects as the cause of a dangerous failure. The results of the expertise were questioned and the thesis was formulated that the process of the rocker failure was initiated during the theft of wheels by raising the car in a manner inconsistent with the manufacturer's instructions. A simulation of this event was carried out by lifting the vehicle on the trailing arm. To assess the effort of the rocker, the photoelastic coating technique was used. The analysis of the measurement results showed that the theft incident could not initiate the fatigue process that led to the failure of the trailing arm.
\end{abstract}

\section{Introduction}

When driving a van car with normal operational load, on the motorway at the permitted speed, the driver of the vehicle began to feel the rear axle swimming, which indicated losing the stability of moving. Despite the driver's attempt to control this phenomenon, the car became unsteady after a while, which led to hitting the protective barrier, performing several revolutions around the center of gravity of the vehicle and finally stopping on the road.

In the insurance indemnification procedure, a visual inspection of the damaged elements was carried out routinely, which confirmed the course of the accident described by the driver, and also showed a cause and effect relationship between the damage to the right longitudinal rear trailing arm of the car and the incident. In particular, the fact that the trailing arm failed while driving the car with a relatively small mileage (about $37000 \mathrm{~km}$ ), led to metallographic expertise of the damaged part of the suspension [1]. It pointed to production defects as the source of fatigue processes initiation, which resulted in the abovementioned trailing arm failure.

As an incident of a theft of wheels was registered in the vehicle history, the manufacturer's representative questioned the results of the expert opinion and indicated the plastic strain occurring while lifting the car on the rocker as the primary source of its damage. Thus, in order to experimentally verify this thesis, it was decided to conduct an experimental simulation of the theft of the wheel and determine the values of the stress and the places of its concentration.

\section{The object and measurement method}

The tests were carried out on the trailing arm of a brand new rear suspension beam of the same car model. It was decided to use a surface method for measuring strains, i.e. a photoelastic coating technique [2,3]. It allows to evaluate the state of strain and stress on the surface of an object covered with a thin layer of material exhibiting the effect of birefringence. Optical effects observed in polarized light are related to the parameters of the strain field (and in the linearelastic range - with stress), which allows for qualitative and quantitative analysis. 
The basic relation defining the relationship between the optical effect (so-called isochromatic fringe order) and the principal strain difference is:

$$
\varepsilon_{1}-\varepsilon_{2}=N \cdot f_{\varepsilon}
$$

where: $N$ - isochromatic fringe order, $\left(\varepsilon_{1}-\varepsilon_{2}\right)$ - difference of the principal strains, $f_{\varepsilon}$ - strainvalue of the coating.

Due to the shape of the swingarm surface, the photoelastic coating in the form of so-called contour plate with a thickness of $t_{c}=2.5 \mathrm{~mm}$, was made of epoxy resin and then bonded with a reflective glue. The rear axle view, with the visible coating glued on the arm, is shown in Figure 1.

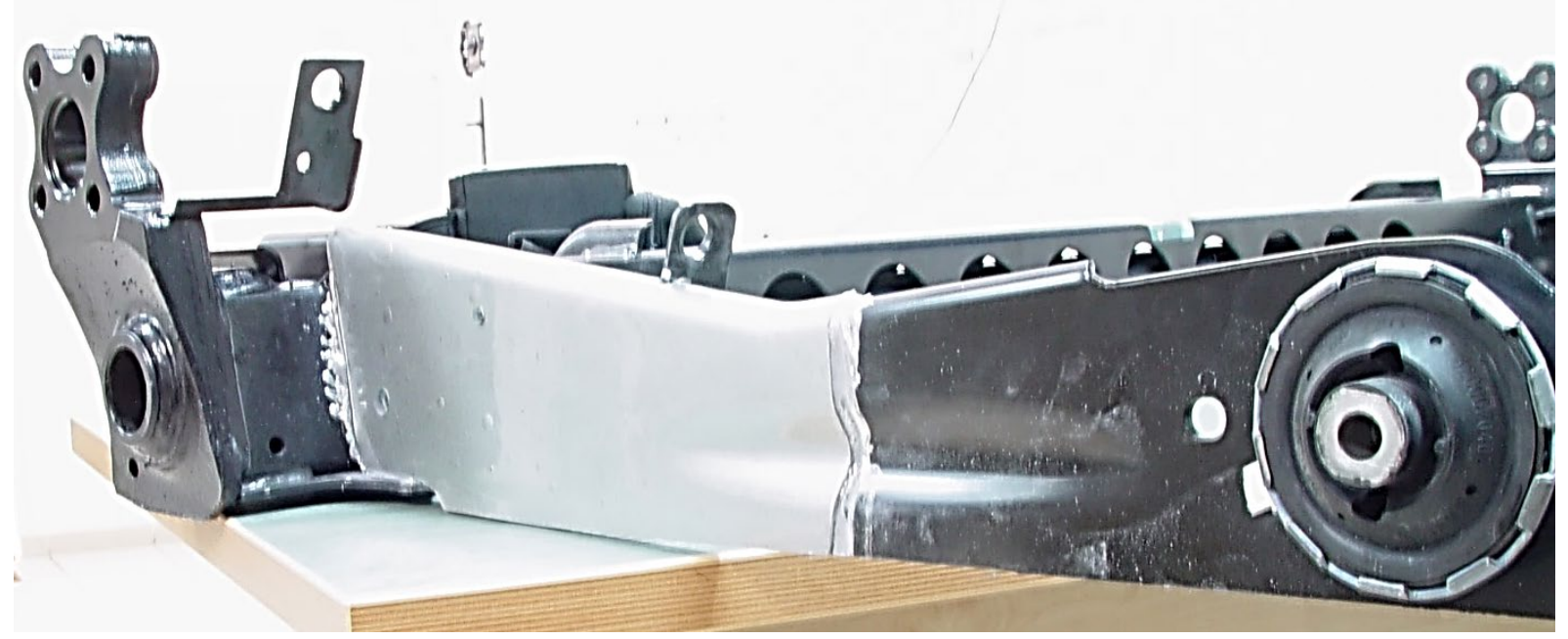

Fig. 1. View of the photoelastic coating on the trailing arm's side surface

The rear beam prepared in this way was mounted in the same, technically efficient car model.

\section{The measurements procedure}

In the discussed experiment, the simulation of lifting the car in a manner inconsistent with the operating instructions, was carried out in the polygon conditions. By using a telescopic screw jack acting directly on the trailing arm (in a place defined by the wheel outline), the right rear wheel was lifted and the photoelastic effects were recorded. At the same time, the height of the selected body point was measured. The measurements started from state A, which corresponded to the minimum lift height of the rocker enabling the wheel removal, and ended by resting the rocker on bricks (state $\mathrm{E}$ ).

The measurements were carried out using a Vishay reflective polariscope (model 031) and a Sony digital camera. The images of full- and half-order isochromatic fringes were recorded, and also the isochromatic fringe order was compensated at selected points of the photoelastic coating. The photoelastic images for individual lifting phases are shown below. 


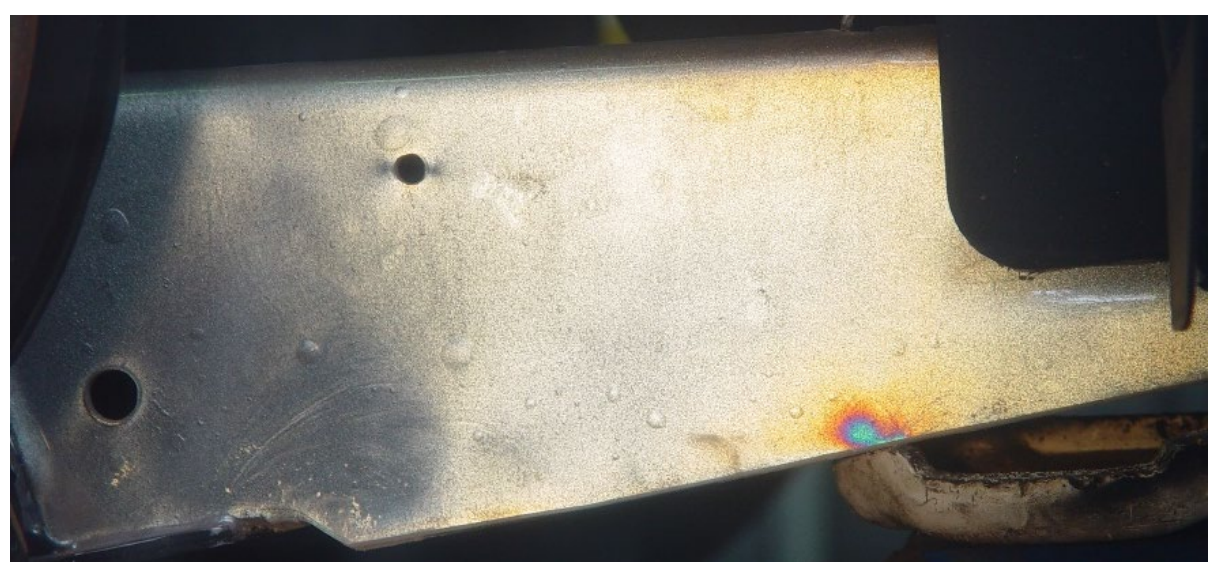

Fig. 2. Full-order isochromatic fringes - lifting phase $A\left(N_{\max } \cong 1.1\right)$

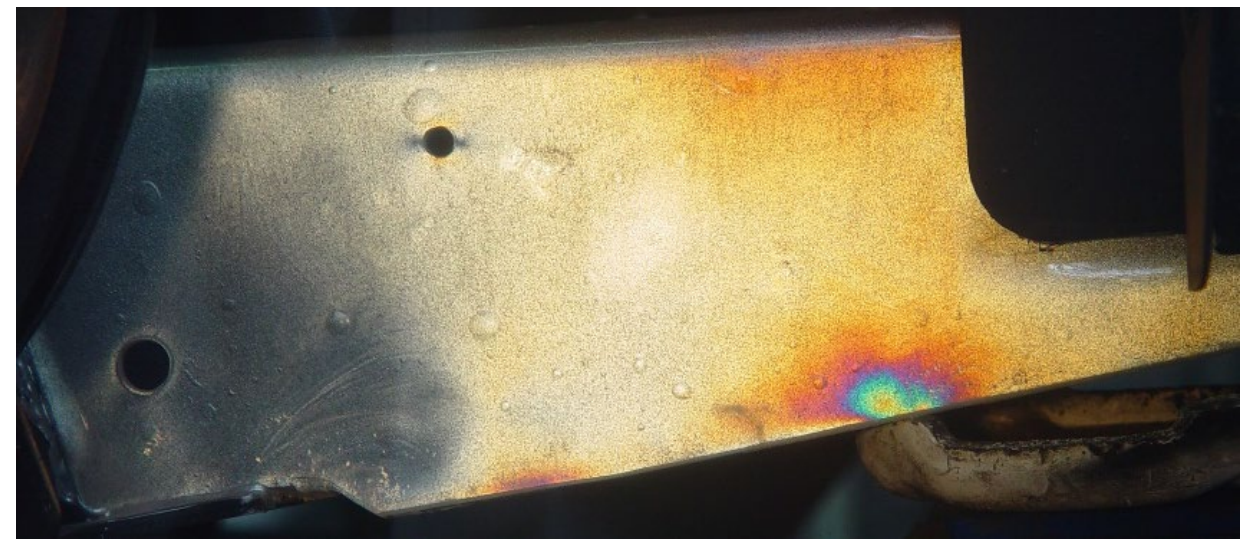

Fig. 3. Full-order isochromatic fringes - lifting phase $B\left(N_{\max } \cong 1.5\right)$

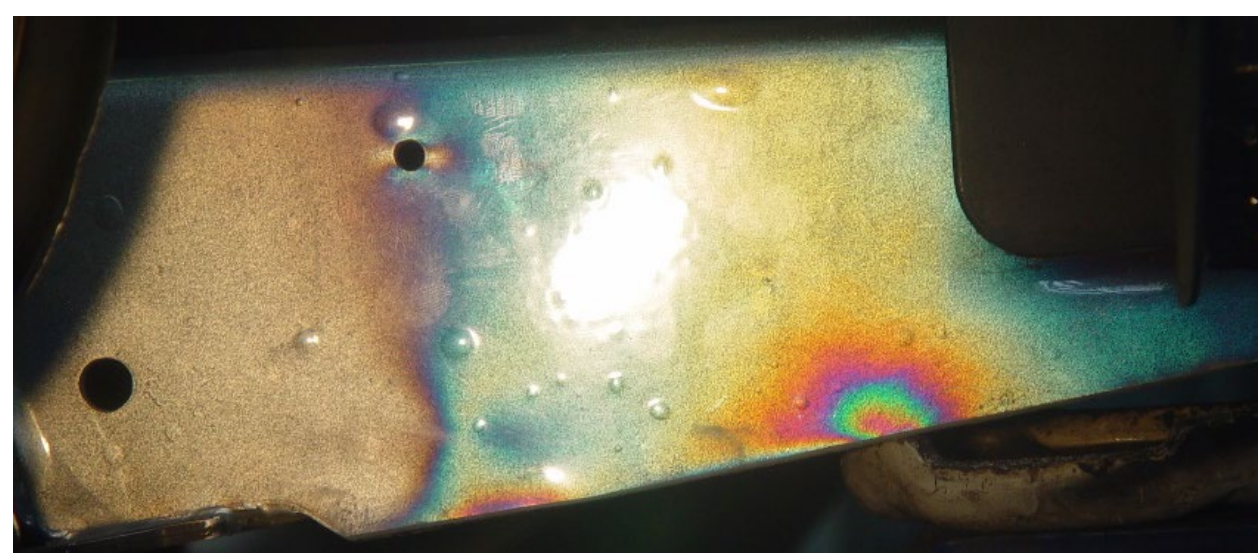

Fig. 4. Half-order isochromatic fringes - lifting phase $C\left(N_{\max }=2.35\right)$ 


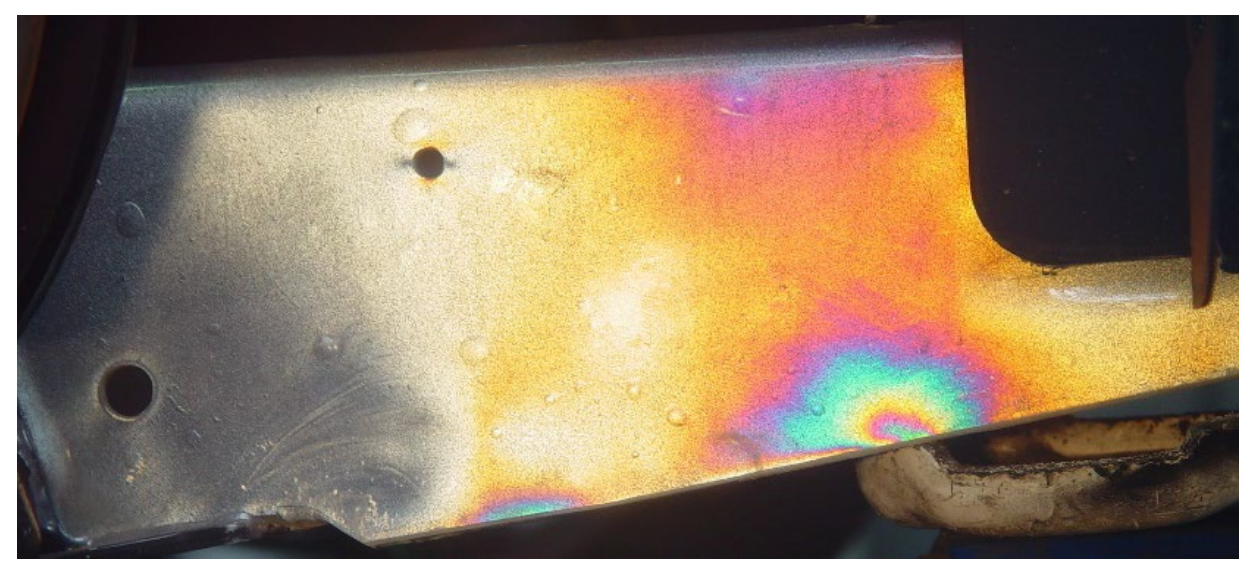

Fig. 5. Full-order isochromatic fringes - lifting phase $D\left(N_{\max } \cong 2.0\right)$

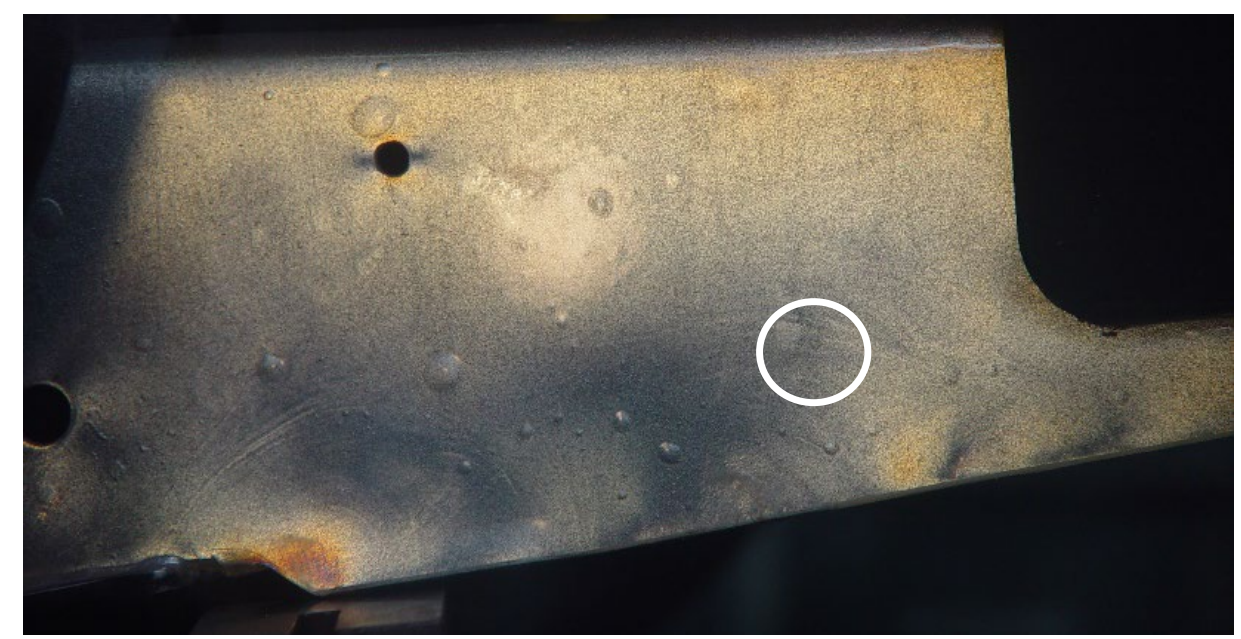

Fig. 6. Full-order isochromatic fringes - phase E (supporting on the bricks) $\left(N_{\text {circle }} \cong 0.3\right)$

\section{Analysis and results}

When analyzing registered isochromatic images, the location of maximum isochromatic fringe order $\mathrm{N}$ was compared with the fracture line in the rocker damaged during the accident - Fig. 7a. This fracture runs through the hole for fixing the handbrake cable, approximately perpendicularly to the upper edge of the rocker, and it is located in the area covered by the wheel(!). Fig. 7b shows its course from the inside in a sample cut for the metallographic research. As it can be seen, the fracture also runs through the end of the weld fixing the reinforcement (rib) to the rocker.

In contrast, during the wheel theft simulation, the maximum values of the isochromatic fringes occurred in the place of impact of the jack head on the lower edge of the trailing arm, away from the fracture. 

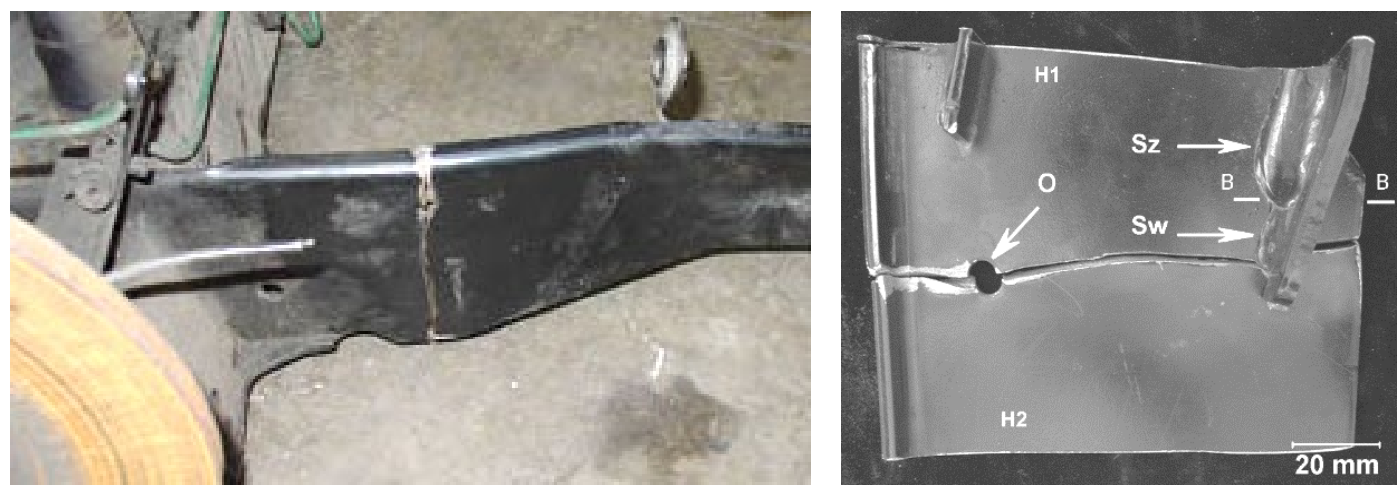

Fig. 7. View of the fracture line: a) from the outer side of the arm, b) from the inside (view rotated $90^{\circ}$ to the left, $\mathrm{Sz}$ - main weld, Sw - preliminary weld, $\mathrm{H1}, \mathrm{H} 2$ - designation of sample fragments)

Because the point impact of the jack head is practically the most unfavorable case of the suspension arm load (in order to enable a wheel removal), it was assumed that the quantitative analysis of photoelastic images would be limited to estimating the stress value acting tangentially to its lower edge, in the immediate vicinity of the jack head.

For this purpose, the so-called the stress value of the isochromatic fringe $f_{\sigma}$ was calculated:

$$
f_{\sigma}=\frac{E_{o}}{1+v_{o}} f_{\varepsilon}
$$

where: $E_{o}$ - object's modulus of elasticity $\left(E_{o}=2.05 \times 10^{5} \mathrm{MN} / \mathrm{m}^{2}\right), v_{o}$ - object's Poisson's ratio $\left(v_{o}=0.3\right), f_{\varepsilon^{-}}$strain-fringe value (in the case under consideration $f_{\varepsilon}=1.105 \times 10^{-3}$ ). The value of normal stress acting tangentially to the edge of the rocker is determined by the formula:

$$
\sigma_{1}=N f_{\sigma}
$$

The maximum stress values for lifting phases are given in Table 1.

Table 1. Maximum stress at the lower edge of the trailing arm

\begin{tabular}{|c|c|c|}
\hline $\begin{array}{c}\text { Lifting } \\
\text { phase }\end{array}$ & $\begin{array}{c}\text { Height of the car } \\
\text { body }[\mathrm{mm}]\end{array}$ & $\begin{array}{c}\sigma_{\max } \\
{\left[\mathrm{N} / \mathrm{mm}^{2}\right]}\end{array}$ \\
\hline A & 258 & 191.7 \\
\hline B & 265 & 261.4 \\
\hline C & 270 & 409.5 \\
\hline D & 275 & 348.5 \\
\hline E & support on the bricks & 174.3 \\
\hline
\end{tabular}

During the lifting, an increase in the stress value was initially observed (max approx. $410 \mathrm{~N}$ $/ \mathrm{mm}^{2}$ in phase C), followed by its decrease due to the inclination of the body and the shift of the vehicle center of gravity to the left (phase D). After removal of the jack and support on bricks, a low isochromatic fringe order $(N \approx 0.3)$ was observed at the location of the jack head impact (area marked with a circle in Fig. 6), so the yield point was exceeded in this region; however, the stress corresponding to the plastic strain reached only approx. $50 \mathrm{~N} / \mathrm{mm}^{2}$.

\section{Summary}

The simulation of lifting the vehicle on the rear arm excludes the possibility of fatigue processes being initiated by this incident. A large distance of the fracture line from the region in which the 
maximum stress values were observed (and after the removal of the jack - low value of the plastic deformation), confirms this conclusion.

It should be emphasized that the metallographic expert opinion [1] clearly indicated the focus of the crack in the joint connecting the reinforcing rib to the arm. Other findings included:

- the ending of the connecting joint $(8 \mathrm{~mm})$ and the main joint $(20 \mathrm{~mm})$ before the end of the reinforcing rib, visible in Fig. 6b,

- no weld penetration (Fig. 7),

- gas bubble in the weld and non-metallic inclusions originating from the paint layer (not removed before welding - Fig.8).

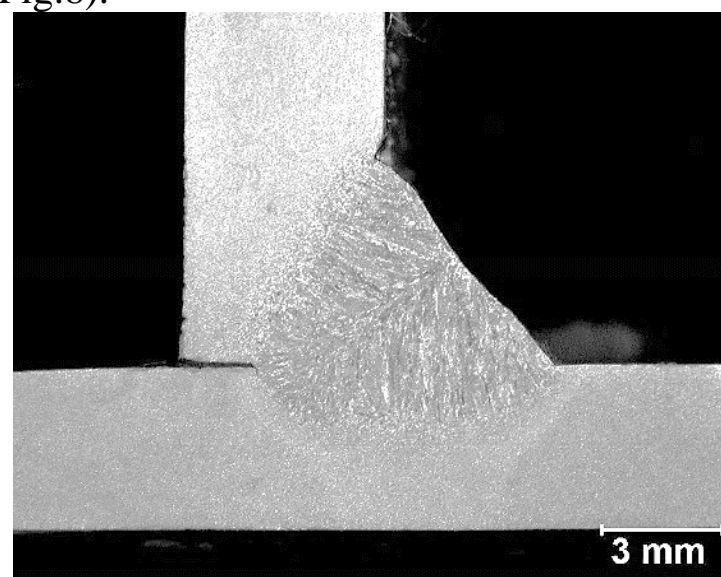

Fig. 7. No penetration in the joint connecting the rib to the trailing arm

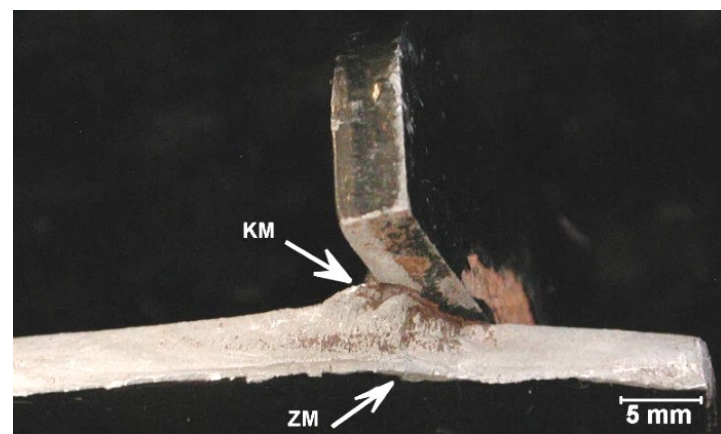

Fig. 8. The view of the fracture in the rib's area - the lack of penetration and not removed varnish layer (KM - fragile fracture zone, ZM - fatigue zone)

Each of these defects causes stress concentration, which in combination with a variable load resulted in the formation of fatigue-type fracture with a ductile fracture zone.

Therefore, the failure is not a result of an improper operation and it was not caused by the user of the vehicle.

\section{References}

[1] W. Dudziński, M. Lachowicz, Metallographic examination of car axle components after an accident (in polish), unpublished expert opinion, Wroclaw University of Science and Technology (2004)

[2] J.W. Dally, Experimental Stress Analysis, third ed., McGraw-Hill, Inc., New York, 1991.

[3] A. S. Khan, X. Wang, Strain Measurements and Stress Analysis, first ed., Prentice Hall, 2001. 